\title{
An Overview of Information and Communication Technology (ICT) in Jordan: Review the Literature of Usage, Benefits and Barriers
}

\author{
Anas Al Bakri \\ Department of Management and Marketing, College of Business and Economics (CBE), Qatar University, Doha, Qatar \\ Email: anasbakri@qu.edu.qa
}

Received March 27, 2013; revised April 28, 2013; accepted May 10, 2013

Copyright (c) 2013 Anas Al Bakri. This is an open access article distributed under the Creative Commons Attribution License, which permits unrestricted use, distribution, and reproduction in any medium, provided the original work is properly cited.

\begin{abstract}
This paper presented a background of the extent of the ICT, IT, and EC-B2B in Jordan. It was mentioned that the development of the ICT in Jordan brings benefits to the enterprises and their TPs. In this paper the EC-B2B systems' readiness in Jordan is defined as the degree of preparation of a nation or community to participate in and benefits from ICT development. The government in Jordan has taken forceful measures towards adoption IT and IS applications and Internet awareness. In 2010, it was reported from the DOS in Jordan that the percentage of individual Internet usage did not exceed 4.7 percent of the population in Jordan [1]. This paper highlighted through subsections on the benefits and risks faced EC-B2B system adoption in Jordan. Based on the recent studies and reports in Jordan, the EC-B2B system adoption was mainly adopted by large enterprises in the supply chain rather than by SMEs. The study concluded that the main two barriers of ICT development and adoption in Jordan are organizational readiness including lack of new education methods, and lack of information and knowledge.
\end{abstract}

Keywords: Information Technology; Electronic Commerce; Electronic Government

\section{Introduction}

The following briefly sets out the governmental, educational and business uses of IT and IS in Jordan, and is followed by a more specific examination of ICT adoption by SMEs. The great development is that ICT brings benefits to enterprises and their TPs, however, these benefits require planning, knowledge and deep understanding [2,3]. Additionally, this technology comes with a lot of barriers that need to be overcome such as security, infrastructure, and legal issues to name a few [1,2]. Therefore, it is important to investigate and analysed the totality of the benefits of ICT adoption, which will definitely affect the marketing behavior of enterprises and their TPs in the near future [4]. UNCTAD stated that enterprises in developing countries that are, or plan to be, involved in international trade need to start incorporating ICT and the Internet into their business models in order to stay competitive [5-7]. The Jordanian Ministry of Information and Communication Technologies (MICT) defines "ICT readiness" as the degree of preparation of a nation or community to participate in and benefit from ICT development $[8,9]$. In addition, the Economist Intel- ligence Unit reported that Jordan was ranked 54th worldwide (out of 68 entries) according to the IT and IS readiness rankings [10]. This indicates that many conditions are suitable to conduct EC-B2B systems initiatives by Jordanian enterprises, although improvement and research is needed to support an environment more conducive to electronic commerce in Jordan.

\section{IT and IS in Jordan}

Many studies such as reference [11-15] show that ICT was widely used in education and training development in Jordan. Recently, the Microsoft Corporation agreed to provide training courses to IT students at the Yarmouk University (a public university in Jordan). At the same time, the Jordanian government has realized the importance of education in developing IT and IS fields and mandated fundamental reforms to introduce computerbased education in public and private schools [16]. The Government of Jordan has taken forceful measures towards adopting IT and IS applications and Internet awareness. It has agreed on directions to make computer education a principal component in elementary schools 
$[1,6]$. In response to these initiatives, many IT and IS enterprises have been established in Jordan as noted by MICT. The following briefly describes the main IT and IS enterprises in Jordan:

1) National Information Centre (NIC) is one of the centres of the higher council of science and technology, established to take the responsibility of developing and managing a national information system in Jordan [8].

2) Royal Scientific Society (RSS) is a non-profit institution. It aims to conduct scientific and technological research and development work related to the development process in Jordan with special attention to industrial and services research [8].

3) Jordan Computer Society (JCS) is the first institution in Jordan taking care of the computer business in Jordan. The JCS is a professional, scientific and social society that concerns itself with the affairs of individuals and companies operating in all IT and IS related lines of works, and activities to improve the level of professionalism in the IT and IS fields through the society's committees [8].

4) Information Technology Association-Jordan (Int@j) is a recent voluntary non-profit IT and private enterprise in Jordan. The mission of Int@j is to effectively represent, promote and advance the Jordanian software, IT and IS services industry in the local and global markets [8].

5) Jordan Telecommunication Company (JTC) is a telecommunications provider in Jordan. The services from JTC aim to meet the needs of customers, generate viable returns for business, secure a competitive position, and meet the license obligations to support the Jordanian economic and social development. Full automation and computerization of all activities and operations, especially with regard to customer care and service centres are some of the developments that have been implemented [17].

6) Telecommunication Regulatory Commission (TRC) is a regulatory agency exercising over telecommunications services in Jordan. TRC aims to realize an effective working relationship among the cities, consumers, service providers and equipment suppliers to facilitate the growth of high-quality, cost-effective and reliable telecommunications services in Jordan [8].

Internet and communication service providers in Jordan are divided into two major areas: the larger global operator-backed Internet Service providers (ISPs) and the smaller ISPs. The global operators allow the smaller ISPs to offer a number of global services such as Global Frame Relay. However, in a market that is struggling to expand, due to a limited corporate market size, as well as the larger problem of unaffordable personal computers (PC), ISPs are finding it difficult to penetrate into what could be a potentially profitable market $[4,18,19]$. Some
ISPs, such as Batelco-Jordan and LINK dot NET have started bundling PCs with Internet access to solve this problem $[8,20]$. Consequently, ISPs tend to inflate their reported subscriber figures in an effort to best position and market themselves as the most popular and successful ISP to potential subscribers. However, despite many efforts to inflate their figures, it would be fair to state that the actual number of Internet subscribers is still low and that Internet cafés will continue to flourish as long as the cost of personal computers (PCs) remains unaffordable by Jordanian standards. Nevertheless, a number of Jordanian governmental bodies have repeatedly attempted to impose strict regulations on the operations of Internet cafés, blocking content, requiring identifications for users, and a number of other rules that form obstacles to increased penetration rates. Reference [21] illustrated that in 2007 Jordan Telecom (JT) began providing the backbone, or physical connection, for Asynchronous Digital Subscriber Line (ADSL), while ISPs may provide the Internet access end of the service to users. This arrangement has not been viewed well by local ISPs, which ISPs claim has been quite unsuccessful due to the backbone exclusivity of the service by Jordan Telecom. The potential ADSL customers such as individual and enterprises must first go through Jordan Telecom to obtain physical access to ADSL before looking for suitable ISPs to provide Internet access. In addition to the problems of dealing with two parties, the customer is then charged both by JT and the ISP, making what ISPs view as an unfriendly and complicated uptake of the ADSL service [1]. Despite Jordan enjoying a liberalized Internet and data provision market, which is currently served by eleven ISPs, it is clearly still facing a number of obstacles that are impeding potential growth. ISP consolidation will evolve in an industry where volume and scale are very important. Many studies in Jordan expect that the consolidation trend will continue in Jordan, bringing the number of ISPs down to seven by 2011 [1]. Jordan Telecom (JT) provides ADSL services to 31 areas in Jordan. In addition, Jordan Telecom (JT), reports that it has an average of 150 new connections per month and the operator reports that early in 2010 it reached a target of 7000 ADSL subscribers. The service is mainly provided to citizens and enterprises with 60 percent of subscribers being businesses. In addition, under a government initiative to provide nationwide connectivity to Jordanian students, a project headed by the Ministry of Education has extended ADSL to 450 schools across the country [1]. The IT sector in Jordan has emerged as a strong economic player since 1995. IT is responsible for the direct growth in value-added economic outputs that have considerable effect on the growth of the national economy, such as education, public administration, business service entities and manufacturing industries [17]. 
In addition to computer software and hardware, Jordan's IT industry also includes the telecommunications sector. The IT sector in Jordan includes the following fields: software development; hardware and packaged software sales; communication equipment; telecommunications services; Internet services; Wireless Application Protocol (WAP); data and information transmission; management services; IT training; consulting and research. Table $\mathbf{1}$ provides the indicators of IT and IS penetration in Jordan.

\section{ICT Initiative in Jordan}

The goal behind the ICT initiative in Jordan is to develop Jordan as a regional ICT hub and a competitive exporter of ICT products and services. This initiative focuses on enhancing the complementary roles and functions of the MICT and TRC in Jordan to accelerate E-government initiative to streamline government operations, generating new ICT opportunities and strengthening partners [8,22-24].

The main project or training program provided by the National Fund for Enterprise Support (NAFES) in Jordan is IT and EC applications. The Information Technology Association of Jordan (Int@j), in cooperation with Arab Advisors Group, is conducting a study on "Internet use among SME in Jordan”. The study aimed to provide decision makers, operating ISPs and investors with a detailed study and assessment of the current use of Internet and EC systems in Jordan. The Int@jprovides also communication services and all new technologies adopted within Jordanian SMEs. In addition, Int@j’s study provides an assessment of the enterprises' future needs and the challenges facing the adoption of EC applications such as B2B, and Internet services by Jordanian enterprises $[8,21,25]$.

\subsection{Internet ADSL in Jordan}

The ADSL service is a method to increase communication speed through the use of a copper cable. ADSL facilitates the division of capacity into channels, with

Table 1. The indicators of IT and is in Jordan in 2012.

\begin{tabular}{cc}
\hline Criterion & Number \\
\hline Internet participants & 70,000 \\
Percentage of computer owners & $4 \%$ \\
The percentage of internet users & $4.7 \%$ \\
Internet providing companies & 11 \\
Fixed phones & 733,000 \\
The percentage of mobile users & $22 \%$ \\
Companies for web design & 50 \\
\hline
\end{tabular}

Source: (DOS Jordan in figures: Economic indicators, 2010). higher speed to the subscribers typically for video communication, and a channel with significantly lower speed in the other direction. Table 2 provides a summary of ISPs in Jordan that provide ADSL service to individuals and enterprises. It also shows the rates for this service.

\subsection{Internet Leased Lines in Jordan}

Leased lines are two interconnected fixed points connected across a private network. Leased lines are dedicated circuits that for example, the JT operator runs directly between two customer sites, providing a permanent connection at a certain speed between the two sites. A leased line with an Internet connection provides permanent access to the Internet with no interruptions or wastage of time [8]. Currently, leased lines are the most popular method of connecting large, small and medium enterprises networks in Jordan.

\subsection{Web Hosting and E-Mail Server Hosting in Jordan}

Web hosting is a service performed by the ISPs or a web development/hosting company, which encourages enterprises to put their enterprise web sites on computers/ servers owned by the ISPs, or the web development company. In general, there are three main types of web hosting approaches in Jordan: (1) Shared Server, (2) Virtual Private Server (VPS) and (3) Dedicated Server. E-mail server hosting is also offered in Jordan whereby an ISP hosts an outside enterprise's e-mail server at its own premises and provides customer support [8].

\section{Electronic Commerce (EC) Systems in Jordan}

Electronic commerce (EC) systems can be divided into two levels [12,26]:

1) The simple level of EC systems covers the promotion and advertising of products and services, and elec-

Table 2. Internet ADSL service providers and rates in Jordan 2012.

\begin{tabular}{|c|c|c|c|c|c|c|c|c|}
\hline \multirow{3}{*}{ ADSL-ISPs } & \multicolumn{4}{|c|}{ Enterprise } & \multicolumn{4}{|c|}{ Residential } \\
\hline & \multicolumn{2}{|c|}{ Monthly } & \multicolumn{2}{|c|}{ Yearly } & \multicolumn{2}{|c|}{ Monthly } & \multicolumn{2}{|c|}{ Yearly } \\
\hline & JD & US & JD & US\$ & JD & US\$ & JD & US\$ \\
\hline Batelco Jordan & - & - & 900 & 1268 & 56 & 79 & 600 & 845 \\
\hline $\begin{array}{l}\text { Global One } \\
\text { (Jordan) }\end{array}$ & 49 & 69 & 528 & 744 & 49 & 69 & 528 & 744 \\
\hline Cyberia-Index & - & - & 700 & 986 & 65 & 92 & 650 & 915 \\
\hline Link dot Net & 141 & 199 & 1356 & 1910 & 73 & 103 & 678 & 955 \\
\hline NEXT & 80 & 113 & 960 & 1352 & 80 & 113 & 960 & 1352 \\
\hline MEC & - & - & 900 & 1268 & - & - & 600 & 845 \\
\hline
\end{tabular}

Source: (MICT 2011). 
tronic distribution of goods.

2) The advanced level of EC systems includes the payment and distribution at the local and global level.

With regard to the extent of EC systems activity, it is very small in Jordan. The delay in the adoption of EC systems in Jordan resulted from the limited number of owners of computers, because of high prices compared with annual income per capita. Reference [26] in his study identified that there are some barriers: financial, legal and the lack of awareness of institutions to deal with this type of EC system. As for the experience of enterprises in Jordan in EC systems, most large enterprises are connected to the Internet to attract customers and often do not aim at sales. The development of EC systems in SMEs requires the support of these enterprises in terms of technical and financial resources [27]. In Jordan, Amman Industry Chamber (AIC), Chamber of Commerce (COC), and the Exports and Trade Development (ETD) are considered the most important institutions in Jordan for the promotion of EC systems. These institutions noted that there must be training and increases in the number of workers on EC systems in order to strengthen its role, as well as awareness campaigns for businesses, especially SMEs [8]. The AIC and Export and Imports Development Foundation (EIDF) are the most effective in stimulating electronic trade to their members. The EIDF set ambitious plans to stimulate EC systems in SMEs to establish sites on the Internet. One of the most important directions of EIDF is to develop a legal framework as well as the creation of a national body that promotes EC systems and encourages enterprises to engage in this area as well as providing technical support needed by enterprises [18]. Furthermore, the use of EC systems by international enterprises in Jordan plays a major role in raising overall awareness and the promotion of EC systems, by providing financial and technical support for private and public sectors. EC systems hold the potential to fundamentally change SMEs. For enterprises, the EC systems may allow all enterprises to easily offer innovative products and services and access to new local and global TPs [28]. At the same time, enterprises that adopt EC systems must develop different methods of conducting business, including methods that may introduce new risks and barriers to the enterprise. For SMEs, the EC systems introduce competitive pressures that may bring significant changes. The following points present the two main adopted forms of EC systems in Jordan.

1) Business-to-Business (B2B) Systems

This is the most common form of EC systems in Jordan. B2B-EC systems run between enterprises and TPs. The report by Reference [25] noted that globalization is the strongest driver for B2B-EC systems in Jordan, since multinational corporations have increasingly been sys- tematic in requiring their regional distributors to do business with them solely via electronic channels. In addition the Jordanian government's support is the second most important accelerator for B2B- EC system adoption in Jordan. Other B2B system drivers include the longterm cost savings usually associated with EC systems, increased collaboration with TPs and the potential for new business opportunities brought about by access to new international markets [25,29,30].

2) Business-to-Consumer (B2C) Systems

The use of the B2C systems form of EC systems is limited in Jordan, where there are only a few enterprises with sites on the Internet and wish to sell to the consumers. Often the aim of this form is to expose the products to the consumers in Jordan. As the trend of online consumer shopping gained firm acceptance worldwide, many enterprises in Jordan established B2C-EC systems' channels to facilitate sales to their consumers through the Internet. B2C-EC systems started to gain popularity mainly among sellers of flowers, gifts, books, software and hardware $[25,31,32]$. In addition the ESCWA's report mentioned that during the past two years, the tourism industry (service sector) has achieved tremendous growth, partly due to the presence of some world-class airlines, hotel chains and resorts in Jordan. Hence, due to online reservations, the airline and hotel segments of the tourism industry have become the fastest growing in terms of B2C-EC systems' transactions in Jordan [25]. However, the lack of use of this form by consumers has resulted from uncertainty in conducting enterprise transactions through the Internet $[25,33]$.

\subsection{Usage of EC Systems in SMEs in Jordan}

The Internet is becoming more common in communications and transactions between enterprises and TPs. Many transactions such as inventory queries, invoices, order placement and confirmation and market research to find suppliers of products is Internet-based [12,13,26]. The adoption of EC systems by enterprises is expected to result in a reduction of the transaction costs that are incurred by these enterprises [9,14,34]. Its significance lies in the fact that it is a tool used by enterprise managers to enhance productivity, as well as to increase the performance of the enterprise by creating a knowledge-based economy and improving educational outputs [35]. SMEs may use EC systems to collect information concerning buying and selling to provide information about products and services and to present help and support for TPs. A report by the Arab Advisors Group based on a survey (of close to five percent of Jordan's SMEs) showed a satisfactory level of adoption of EC systems by enterprises in Jordan [36]. Nonetheless, the report also noted that Jordanian SMEs needed to have more awareness of IT adoption that could better restructure their functions and ac- 
tivities with TPs [27]. Recent studies in one of the northern cities in Jordan (Irbid) showed that ICT and IS such as B2B, B2C, Government-to-Business (G2B) and EC systems were a dynamic value-added aspect of the economy and played an important role in driving major economic sectors in Jordan [12,37]. Reference [38] noted that because of inefficient strategies and action plans of EC systems in Jordan, only several of the functions, activities and procedures in large enterprises in relation to their local and global TPs are conducted over the Internet and are performed by managers. In 2010, it was reported that the percentage of individual Internet usage did not exceed 4.7 percent of the population in Jordan. It was also reported that there were only 11 Internet providing companies (IPs), whereas the number of companies for Web design was 50. Ownership of computers in SMEs is also low $[1,39]$.

\subsection{Barriers of EC System Adoption in Jordan}

There are many different potential barriers that could limit the adoption of EC systems, such as privacy and security issues; skills and expertise; readiness of customers and suppliers; legal and regulatory environment; infrastructure; business strategies; cost; awareness and knowledge [40-42]. In addition, risks and barriers are very important in understanding the adoption behavior of SMEs [43-46]. Barriers regarding organizational readiness include lack of new education methods, and lack of information and knowledge. The barriers, which limited the spread of EC system adoption in Jordan, are summarized as follows [12,37,47-49]:

1) Lack of understanding of the significance for consumers on the need to conduct transactions online.

2) There is a barrier by some companies to access confidential information about competitors.

3) Barriers related to fraud, deception and piracy.

4) Lack of coordination between sectors in Jordanian market.

5) Limited use of credit cards in international payments through the Internet.

6) Lack of sufficient awareness of the institutions and individuals of e-commerce and the lack of training and education regarding EC systems.

7) Mistrust of electronic payment operations, where there is a belief that the electronic payment may be prone to deception, fraud and unsafe and that there is a lack of a framework and legal protection.

8) Lack of funding for projects relating to EC systems.

9) Absence of an electronic directory of EC systems.

10)The lack of formalized norms and standards for EC systems.

11)No detailed studies exist that identify the behavior of the business community as it relates to the use of the information network and international transactions electronically.

12)Lack of preparedness of banks in Jordan to conduct financial transactions online.

13)Cultural barriers hinder the spread of EC systems, in particular the cultural preference for Jordanian people to conduct business and personal finance transactions personally.

14)Lack of a clear strategy and comprehensive EC systems in Jordan.

\section{Conclusion}

This paper presented a background of the extent of the ICT, IT and EC systems in Jordan. It was mentioned that the development of the ICT in Jordan brings benefits to the enterprises and their TPs. In this paper the EC systems' readiness in Jordan is defined as the degree of preparation of a nation or community to participate in and benefits from ICT development. The government in Jordan has taken forceful measures towards adoption IT and IS applications and Internet awareness. In 2007, it was reported from the DOS in Jordan that the percentage of individual Internet usage did not exceed 4.7 percent of the population in Jordan. This study highlighted through subsections on the benefits and risks faced EC system adoption in Jordan. In addition, this study explored the current extent of the EG in Jordan, which provides various objectives and programmes in support of EG in Jordan compared with other developed and developing countries. Based on the recent studies and reports in Jordan, the EC system adoption was mainly adopted by large enterprises in the supply chain rather than by SMEs. The study concluded that the main two barriers of ICT development and adoption in Jordan are organisational readiness including lack of new education methods, and lack of information and knowledge.

\section{REFERENCES}

[1] Department of Statistics in Jordan (DOS), Census of enterprises, 2011. http://www.dos.gov.jo

[2] N. Black, A. Lockett, H. Winklhofer and C. Ennew, “The Adoption of Internet Financial Services: A Qualitative Study," International Journal of Retail and Distribution Management, Vol. 29, No. 8, 2000, pp. 390-398. doi:10.1108/09590550110397033

[3] V. Zeithaml, A. Parasuraman and A. Malhotra, "Service Quality Delivery through Web Sites: A critical Review of Extant Knowledge," Journal of the Academy of Marketing Science, Vol. 30, No.4, 2003, pp. 362-375.

[4] M. Warren and W. Hutchinson, "Cyber-Attacks Against Supply Chain Management Systems: A Sort Note,” International Journal of Physical Distribution \& Logistics Management, Vol. 30, No. 7-8, 2002, pp. 710-716. doi:10.1108/09600030010346521

[5] J. Caldow, "The Quest for Electronic Government: A 
Defining Vision,” Institute for Electronic Government, IBM Corporation, Washington DC, 1999.

[6] UNCTAD, "Building Confidence: E-Commerce and Development Report,” 2012.

http://www.unece.org/trade/untdid/welcome.htm

[7] J. Westby, "International Guide to Combating Cybercrime,” American Bar Association, USA, 2003.

[8] Ministry of Information and Communication Technologies in Jordan (MICT), "The E-Readiness Assessment of the Hashemite Kingdom of Jordan,” 2011. http://www.moit.gov.jo

[9] R. Schperberg and R. Kenneth, “Cybercrime,” ISACA, Rolling Meadows, 2005.

[10] Economist Intelligence Unit, “The 2006 E Readiness Rankings,” 2012.

http://www.eiu.com/2006ereadinessRankings

[11] R. Gulati, "Business-to-Business E-Commerce: Past, Present, and Future," 2012.

[12] M. Sahawneh, "E-Commerce: The Jordanian Experience, Industrial Studies Department,” Royal Scientific Society, 2002.

[13] M. Stamp, “Information Security,” John Wiley \& Sons, New York, 2005. doi:10.1002/0471744190

[14] C. Steinfield and P. Whitter, "Community level SocioEconomic Impacts of Electronic commerce,” Journal of Computer Mediated Communication, Vol. 5, No. 2, 1999, pp. 714-719.

[15] T. Thanasankit, "E-Commerce and Cultural Values,” Idea Group Inc., New York, 2002. doi:10.4018/978-1-59140-056-1

[16] A. Abu-Samaha and Y. Abdel Samad, "Challenges to the Jordanian Electronic Government Initiative,” Journal of Business Systems, Governance and Ethics, Vol. 2, No. 3, 2007, pp. 101-109.

[17] Ministry of Industry and Trade in Jordan (MIT), 2012. http://www.mit.gov.jo

[18] M. Al-Ibraheem and H. Tahat, "Regulating Electronic Contracting in Jordan,” 21st BILETA Conference; Globalization and Harmonization in Technology Law, Malta, 6-7 April 2006, pp. 6-19.

[19] Organization for Economic Cooperation and Development OECD, "Economic Growth in the OECD Area," OECD Working Paper, 2000.

[20] M. Greenstein and T. Feinman, "Electronic Commerce; Security, Risk Management and Control," McGraw-Hill, Boston, 2000.

[21] Ministry of Trade and Industry in Jordan, 2010. http://www.mit.gov.jo

[22] Organization for Economic Cooperation and Development OECD, "E-Commerce: Impacts and Policy Challenges,” Organization for Economic Cooperation and Development (OECD), Vol. 67, No. 193, 2000, pp. 193202.

[23] Organization for Economic Cooperation and Development OECD, "The Economic and Social Impacts of electronic Commerce,” Preliminary Finding and Research
Agenda, 1999.

[24] Organization for Economic Cooperation and Development (OECD), "E-Commerce: Impacts and Policy Challenges,” 2002.

[25] ESCWA, "National profile of the Information Society in Jordan,” United Nation Report, 2007, pp. 1-16.

[26] M. Sahawneh, "E-Commerce and Its Effect on Labor Force" Socio-economic Impact of Persistent Organic Pollutants,” Royal Scientific Society, 2005.

[27] Arab Advisor Press Room, 2012. http://www.arabadvisors.com

[28] Abu-Ghazaleh and C. Consulting, "Market Brief on Telecommunications Sector in Jordan," 2009. http://www.commercecan.ic.gc.ca

[29] Business Integration Technology, Inc., "Why Supply Chain Executives Should Care about B2B Integration Technology,” 2012.

http://businessintegrationtechnology.com/PDF/WhyB2Bi Matters.pdf

[30] Business Integration Technology Inc., 2012. http://www.businessintegrationtechnology.com

[31] S. Blythe, "Digital Signature Law of the United Nation. European Union, United Kingdom and United State: Promotion of Growth in E-commerce with Enhanced Security," Richmond Journal of Law and Technology, Vol. XI, No. 2, 2005, pp. 1-20.

[32] H. Rank and B. Schmitt, "The Challenge of Information Security,” Military Technology, Vol. 29, No. 11, 2005, pp. 8-50.

[33] T. R. Peltier, "Information Security Risk Analysis,” CRC Press, Boca Raton, 2001.Organization for Economic Cooperation and Development OECD, "The Economic and Social Impacts of electronic Commerce,” Preliminary Finding and Research Agenda, 1999.

[34] A. Al-Bakri, "The Adoption of B2B by SME in Amman and the Perceptions of Its Influence on Their Performance and Efficiency," PhD Thesis (Non-Published Thesis), University of Southern Queensland, Toowoomba, 2009.

[35] D. Kim, S. Cavusgil and R. Calantone, "Information System Innovations and Supply Chain Management: Channel Relationships and Firm Performance," Journal of the Academy of Marketing Science, Vol. 34, No. 1, 2006, pp. 40-54.

[36] Arab Advisor Group, 2012.www.arabadvisors.com

[37] W. Titi, "The Impact of Adoption Electronic Commerce in Small to Medium Enterprises Jordanian Companies," The 1st International Conference on E-Business and ELearning, Jordan, 24-25 May 2005, pp. 159-178.

[38] E. Abu Zaid, “Attracting E-Commerce. First GCC E-Commerce Conference, UAE,” 2005. www.kenzay-traning.com

[39] M. El-Nawawy and M. Ismail, “Overcoming Deterrents and Impediments to Electronic Commerce in Light of Globalization," Proceedings of the 9th Annual Conference of the Internet Society, INET 99, San Jose, 22-25 June 1999, pp. 9-18.

[40] E. M. Heffes, "Refining the Rules of Commerce,” Finan- 
cial Executive, Vol. 17, No. 3, 2001, pp. 3-18.

[41] E. Kritzingera and E. Smith, "Information Security Management: A Previous Term Information Security Retrieval and Awareness Model for Industry," Computers \& Security, June 2008.

[42] T. Layton, "Guide to Information Security," CRC Press, Boca Raton, 2006.

[43] C. Easttom, “Computer Security Fundamentals,” Pearson Prentice Hall, Michigan, 2007.

[44] ESCWA, "Development of E-Commerce Sectors in the Arab Region," World Summit on the Information Society (WSIS), Beirut, 22-25 June 1999, pp. 9-18.

[45] J. Fraser, "The Strategic Challenge of Electronic Commerce,” Supply Chain Management, Vol. 5, No. 1, 2000, p. 7. doi:10.1108/13598540010312936
[46] V. Leopoulos, K. Kirytopoulos and D. Voulgaridou, "the benefits of e-commerce: a case study of the Greek Para-pharmaceutical industry,” National Technical University of Athens, Athens, 2006.

[47] M. Gerber and R. Solms, "Information Security Requirements-Interpreting the Legal Aspects," Computers \& Security, Vol. 27, No. 5-6, 2008, pp. 124-135. doi:10.1016/j.cose.2008.07.009

[48] K. Hausken, "Information Sharing among Firms and Cyber-Attacks," Journal of Accounting and Public Policy, Vol. 26, No. 6, 2007, pp. 639-688. doi:10.1016/j.jaccpubpol.2007.10.001

[49] Y. Rezgui and A. Marks, "Information Security Awareness in Higher Education: An Exploratory Study," Computers and Security, Vol. 27, No. 7, 2007, pp. 241-253. 